\title{
Delta inflation: a bias in the design of randomized controlled trials in critical care medicine
}

\author{
Scott K Aberegg*1, D Roxanne Richards² and James M O'Brien ${ }^{3}$
}

\begin{abstract}
Introduction: Mortality is the most widely accepted outcome measure in randomized controlled trials of therapies for critically ill adults, but most of these trials fail to show a statistically significant mortality benefit. The reasons for this are unknown.

Methods: We searched five high impact journals (Annals of Internal Medicine, British Medical Journal, JAMA, The Lancet, New England Journal of Medicine) for randomized controlled trials comparing mortality of therapies for critically ill adults over a ten year period. We abstracted data on the statistical design and results of these trials to compare the predicted delta (delta; the effect size of the therapy compared to control expressed as an absolute mortality reduction) to the observed delta to determine if there is a systematic overestimation of predicted delta that might explain the high prevalence of negative results in these trials.
\end{abstract}

Results: We found 38 trials meeting our inclusion criteria. Only 5/38 (13.2\%) of the trials provided justification for the predicted delta. The mean predicted delta among the 38 trials was $10.1 \%$ and the mean observed delta was $1.4 \%(P<$ 0.0001 ), resulting in a delta-gap of $8.7 \%$. In only $2 / 38$ (5.3\%) of the trials did the observed delta exceed the predicted delta and only $7 / 38$ (18.4\%) of the trials demonstrated statistically significant results in the hypothesized direction; these trials had smaller delta-gaps than the remainder of the trials (delta-gap 0.9\% versus $10.5 \% ; P<0.0001$ ). For trials showing non-significant trends toward benefit greater than 3\%, large increases in sample size (380\% - 1100\%) would be required if repeat trials use the observed delta from the index trial as the predicted delta for a follow-up study.

Conclusions: Investigators of therapies for critical illness systematically overestimate treatment effect size (delta) during the design of randomized controlled trials. This bias, which we refer to as "delta inflation", is a potential reason that these trials have a high rate of negative results.

\section{"Absence of evidence is not evidence of absence."}

\section{Introduction}

Mortality has become the standard outcome measure in trials of therapies in critically ill adults because it obviates debate about clinical relevance and concerns of ascertainment bias. However, it has recently been noted that the majority of these trials fail to demonstrate efficacy [1] and several therapies that appeared promising did not demonstrate efficacy on repeated study [2-7]. The high rate of negative results in these trials could be explained by several possibilities including true lack of efficacy (the null hypothesis is true), type II statistical errors in trials with

\footnotetext{
* Correspondence: scottaberegg@gmail.com

1 Department of Critical Care, Jordan Valley Medical Center, 3580 West 9000 South, West Jordan, Utah, 84088, USA

Full list of author information is available at the end of the article
}

adequate power, and methodological problems in study design leading to inadequate power and sample size [8].

Several parameters must be chosen by investigators in the design of a trial of mortality in order to determine the required sample size, including the significance level required for rejection of the null hypothesis; power; the predicted mortality rate in the placebo arm; and the predicted effect size (delta). In contrast to significance level and power, which are usually set by convention at 0.05 and $90 \%$, respectively, predictions about the placebo mortality rate must be guided by preliminary data (if available) or guesswork. Likewise, predictions of delta are either based on existing data or are guided by biological plausibility or a minimal clinically important difference (MCID) $[9,10]$. Using these four variables (significance level, power, baseline mortality rate, and delta) sample size required for the trial can be calculated. 
Unfortunately, sample size is often not determined in this fashion [11-13]. As a result of financial, time, and logistical constraints [14], investigators often first estimate the number of patients that they can expect to enroll during the planned duration of the trial with available resources. Then, using conventional values for significance level and power, they calculate the delta that they can expect to find using that sample size, in effect performing sample size calculations in reverse. (It is also not unusual for investigators to revise delta upward midtrial when declining enrollment is noted [15,16].) As a result of this, values of predicted delta used by investigators in study design may not represent a realistic estimate of the effect of a therapy on outcomes. As shown in Table 1 , sample size determinations are much more sensitive to changes in delta than the other three variables; this fact, combined with inflexibility with regard to significance level and power (due to convention), may make delta more susceptible to misuse and manipulation. We refer to biased overestimates of effect size during trial design as 'delta inflation'. If it exists, delta inflation may result in trials that have inadequate sample size to find true differences between a therapy and placebo, leading to a high rate of falsely negative trials, with many attendant implications for critical care research and practice.

\section{Materials and methods}

One author (SKA) performed a search of the tables of contents of five high-impact medical journals (BMJ, New England Journal of Medicine, Journal of the American Medical Association, Lancet, Annals of Internal Medicine) for titles containing the keywords (and variations thereof) critically ill, intensive care, ICU, acute respiratory distress syndrome, acute lung injury, sepsis, shock, ventilator, ventilation, respiratory failure, multiple organ dysfunction, continuous veno-venous hemodialysis, and renal failure, but not containing keywords related to pediatrics (neonatal, infant, children, prematurity) published between 1 January, 1999 and 22 July, 2009. Articles containing included keywords were then reviewed further to determine if they met inclusion and exclusion criteria. Articles were included if they described a randomized controlled trial in a critically ill adult population that evaluated proportional mortality (mortality expressed as a proportion as opposed to that measured as a mean survival or a time to event analysis) as the primary endpoint upon which power calculations were based. Articles were excluded if they described a non-inferiority trial, if they dealt with a non-ICU population (out of hospital, prehospital, or care not described as delivered in an ICU setting), and if they included non-adult patients. Factorial trials testing more than one therapy were considered as separate trials for each therapy tested, even if reported in the same manuscript.

Data were abstracted from articles meeting these criteria utilizing a standardized form. We recorded variables pertaining to statistical methods including significance level, power, delta, the expected baseline (placebo or standard care) mortality rate, the a priori sample size, whether the study was terminated early, and any modifications made to the sample size in the middle of the trial. We recorded whether the predicted delta was justified by reference to either published or unpublished data. We abstracted data from the results of the trial including the number of patients in the treatment and placebo arms that were included in the final data analysis, and the mortality rate in each arm. We recorded unadjusted results and those pertaining to the overall (intention-to-treat) population (so that the results would correspond to the assumptions of the power calculations) even where the authors emphasized adjusted or subgroup analyses. For three trials that did not report the predicted delta, we contacted the authors to obtain this information. For one of these trials [17], the predicted delta could not be determined and the study was excluded. For the other two trials, the authors provided information about the predicted

Table 1: Simulated scenarios for sample size determination in the design of a hypothetical study

\begin{tabular}{|c|c|c|c|c|c|}
\hline & $\begin{array}{l}\text { Standard } \\
\text { Scenario }\end{array}$ & $\begin{array}{c}\text { Relaxed } \\
\text { significance } \\
\text { level }\end{array}$ & Relaxed Power & $\begin{array}{c}\text { Baseline } \\
\text { Mortality shifted } \\
\text { away from } 50 \%\end{array}$ & Inflated delta \\
\hline $\begin{array}{l}\text { Significance level } \\
\text { (two-sided) }\end{array}$ & 0.05 & 0.1 & 0.05 & 0.05 & 0.05 \\
\hline Power & $90 \%$ & $90 \%$ & $80 \%$ & $90 \%$ & $90 \%$ \\
\hline $\begin{array}{l}\text { Baseline (placebo) } \\
\text { mortality rate }\end{array}$ & $50 \%$ & $50 \%$ & $50 \%$ & $40 \%$ & $50 \%$ \\
\hline Delta (ARR) & $10 \%$ & $10 \%$ & $10 \%$ & $10 \%$ & $15 \%$ \\
\hline $\begin{array}{l}\text { Required sample } \\
\text { size }\end{array}$ & 1076 & 884 & 816 & 992 & 480 \\
\hline
\end{tabular}

Inflation of delta has a substantially larger impact on required sample size than changes in the other variables. ARR, absolute risk reduction. 
delta and sample size calculations not included in the original manuscript.

Using these data, we performed confirmatory sample size calculations for each trial, determined the observed treatment effect (delta) and the difference between the predicted and observed delta (the delta-gap), calculated the $95 \%$ confidence interval for the observed delta, and plotted a graph of observed versus predicted delta. We calculated mean predicted and observed delta values across all trials, and compared them using a paired t-test with unequal variances. For non-statistically significant trials that had an observed delta greater than the smallest predicted delta of all the trials ( $3 \%$ [18]), we calculated the sample size that would be required if the trials were to be repeated using the observed delta of the index trial as the predicted delta for the future trial. All statistical calculations were performed using STATA version 8.0 (College Station, TX, USA).

\section{Results}

Our search identified 160 articles for further review. Of these, 58 described trials that were not randomized controlled trials, 46 were excluded because mortality was not the primary outcome on which power calculations were based, 12 were excluded because they dealt with noncritically ill populations, 2 were excluded because they described non-inferiority trials, 1 was excluded because it dealt with pediatric patients, and 1 was excluded because no predicted delta was reported and the authors could not provide the information. The remaining 38 articles were included in our analysis.

Additional file 1 shows the characteristics of the included trials. Among all trials, only 5 of the 38 (13.2\%) provided justification for the predicted delta, and 7 of the 38 (18.4\%) provided justification for the baseline mortality rate used in sample size calculations (data not shown). Among all included trials, 27 of the 38 (71\%) provided sufficient information for us to replicate the sample size calculations. For 20 of these 27 trials (74\%), our sample size calculations yielded values that deviated less than $10 \%$ from the a priori sample sizes specified in the manuscript.

Figure 1 demonstrates graphically the main results of our analysis comparing predicted and observed delta. As seen in Figure 1, values for observed delta are not randomly scattered around the blue line representing unity with predicted delta, but rather fall almost uniformly below it. Among all included trials, only 2 (5.3\%) demonstrated an observed delta equal to or greater than the predicted value $[19,20]$. The mean predicted delta among all trials was $10.1 \%$, the mean observed delta was $1.4 \%(P<$ 0.0001 for this comparison), and the mean difference between predicted and observed delta (the delta-gap) was $8.7 \%$. Among all trials, only 7 of the 38 included studies
(18.4\%) demonstrated an unadjusted delta for the intention-to-treat population that was statistically significant in the hypothesized direction (red triangles above zero on the Y-axis in Figure 1). Among all trials, 26 of 38 (68.4\%) had $95 \%$ confidence intervals for observed delta that did not include the predicted delta, in essence excluding an effect of the therapy as great as the predicted delta. However, 31 of 38 (81.6\%) of the trials had an associated 95\% confidence interval that included a delta of $3 \%$, which was the smallest predicted delta sought by investigators in all of the trials [18].

Among all trials, 17 of 38 (44.7\%) had an observed delta with a negative value (that is, the treatment was numerically worse than the comparator). Three of these trials showed a statistically significant increase in mortality with the therapy, and all of these trials were stopped early for harm $[4,21,22]$. The seven trials showing a statistically significant difference favoring the therapy had a smaller delta-gap compared with non-significant trials and those demonstrating harm (delta-gap $0.9 \%$ versus $10.5 \%$; $P<$ 0.0001). In Figure 1, these seven trials are represented by red triangles above zero on the Y-axis; as can be seen graphically, the deltas associated with these trials fall closer to the blue unity line than the other trials.

For the eight trials that showed a non-statistically significant point estimate for delta that exceeded the smallest predicted delta of all trials ( $3 \%$ [18]), we calculated the sample size that would be required to repeat the study using the observed delta of the index study as the predicted delta for the repeat study. Repeating these trials in this fashion would require increases in sample size from $380 \%$ to $1,100 \%$ compared with the sample size of the index study (data not shown).

\section{Discussion}

We found that randomized controlled trials of therapies in critical care medicine evaluating proportional mortality as a primary endpoint and published in five highimpact medical journals during the past 10 years utilized predicted values of delta in power calculations that systematically overestimated observed values of delta. We propose that this phenomenon of 'delta inflation' represents a bias in the design of such trials with attendant implications for the design of future trials and the practice of critical care medicine.

Our results accord with the findings of a recent report that found low rates of efficacy in trials in critical care medicine, a finding the authors attributed to the use of mortality as an endpoint [1]. We extend this work by identifying a key feature of such trials, namely that the predicted delta almost uniformly over-estimates the observed delta. This phenomenon of 'delta inflation' is a possible reason that many of these trials fail to demonstrate efficacy. Other investigators have found discrepan- 
Aberegg et al. Critical Care 2010, 14:R77

Page 4 of 7

http://ccforum.com/content/14/2/R77

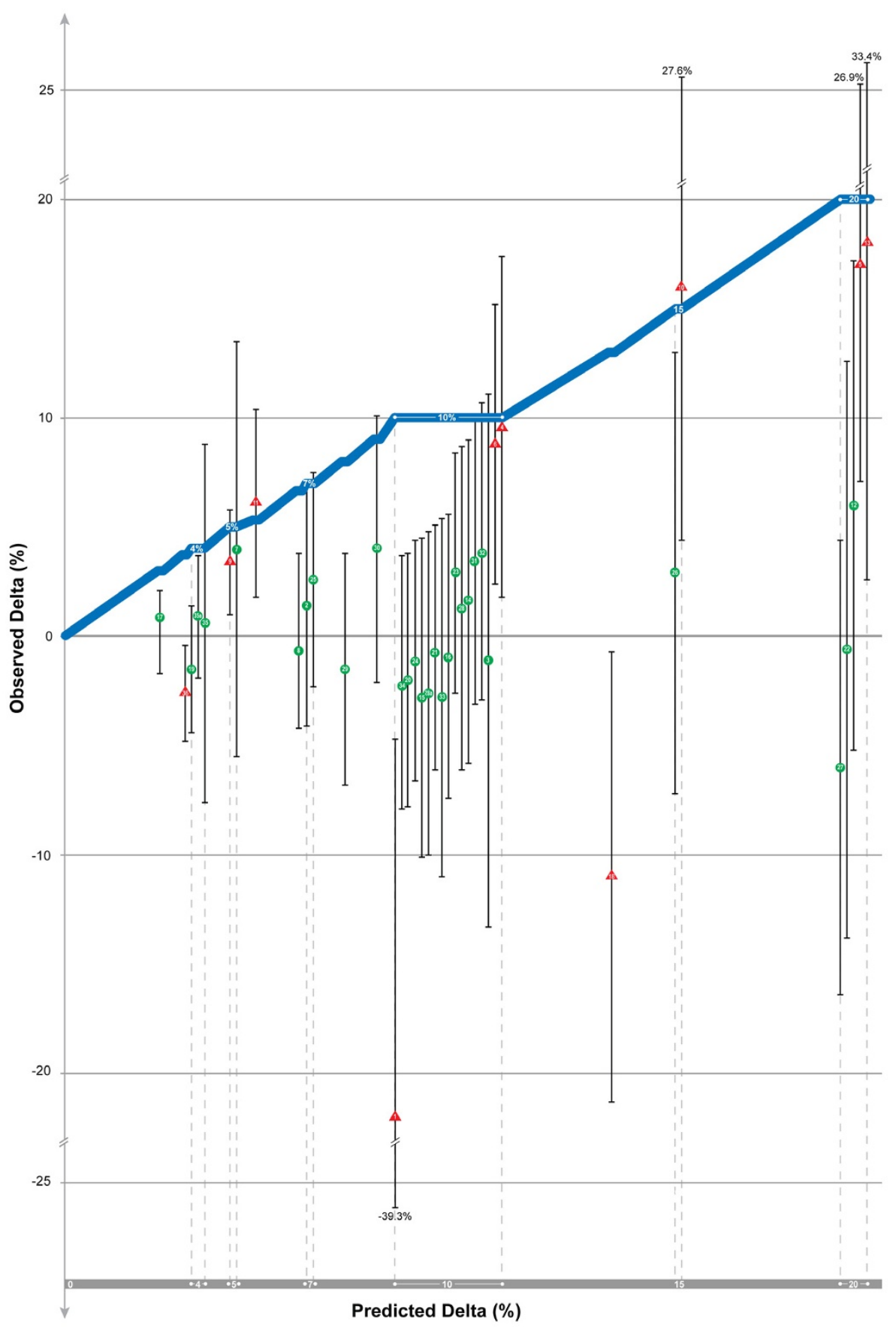

Figure 1 Plot of observed versus predicted delta (with associated $95 \%$ confidence intervals for observed delta) of 38 trials included in the analysis. Point estimates of treatment effect (deltas) are represented by green circles for non-statistically significant trials and red triangles for statistically significant trials. Numbers within the circles and triangles refer to the trials as referenced in Additional file 1. The blue 'unity line' with a slope equal to one indicates perfect concordance between observed and predicted delta; for visual clarity and to reduce distortions, the slope is reduced to zero (and the $x$-axis is horizontally expanded) where multiple predicted deltas have the same value and where $95 \%$ confidence intervals cross the unity line. If predictions of delta were accurate and without bias, values of observed delta would be symmetrically scattered above and below the unity line. If there is directional bias, values will fall predominately on one side of the line as they do in the figure. 
cies between predicted and observed delta in other fields and with other outcomes, but the overall prevalence of delta inflation in clinical investigation is unknown $[23,24]$. Our study also complements reports showing that sample size calculations are inadequately or disingenuously reported in randomized controlled trials $[8,25,26]$. It expands this work by demonstrating that even when there is adequate reporting of statistical methodology, one component of sample size estimation is biased, thus rendering the entire procedure unreliable [9].

The reasons for the discrepancy between predicted and observed delta cannot be determined from our data, but beg speculation. One possibility is that investigators are choosing delta based on sample size rather than choosing sample size based on delta $[8,11]$. Another possibility is that investigators are overly optimistic about the efficacy and effect size of a therapy and that delta inflation is borne of unrealistic optimism [27]. There may also be a belief that effect sizes below some threshold (say, 10\%) are not clinically important, but this is a notion undermined by investigations that sought predicted delta values as low as $3 \%$ and by other evidence $[18,28]$. Moreover, although it has been suggested that delta should be based on an assessment of the MCID, our finding of wide variation in predicted deltas in studies with the same primary outcome demonstrates that this is not happening [29-31]. Publication bias affecting pilot trials may cause those with smaller effect sizes to go unpublished, thereby inflating the apparent benefit of a therapy when and if a literature search is performed [32]; however, the low rate of referenced justification for predicted delta that we and others have documented argues against this [24,33,34]. The insistence on mortality as the gold standard outcome measure in critical care research combined with funding constraints may pressure investigators to search for unrealistic mortality benefits and perhaps to hope that significant improvements in secondary outcome measures will lead to adoption of the therapy $[35,36]$. Indeed, the very concept of power and the so-called 'double-significance' approach to hypothesis testing and sample size determination has been called into question [37]. Finally, a looming possibility is that the null hypothesis is true and most therapies for critical illness simply are not efficacious. Given the wide confidence intervals around observed delta in the trials in our analysis, this is impossible to disprove with existing data. However, the consistent conduct of trials of therapies that are in reality not efficacious basically would consist of an extreme form of delta inflation. In any case, investigators should take stock in the fact that deltas of $10 \%$ or greater are rarely found, and attention needs to be refocused on what is the minimal clinically important difference in trials of therapies to reduce mortality in critical illness $[9,31]$.
Regardless of the causes of delta inflation, its effects are likely deleterious. Firstly, some authors have argued that underpowered trials are unethical and trials designed with delta inflation are essentially underpowered [38]. Secondly, insomuch as delta inflation leads to trials that are 'negative', it may contribute to the premature abandonment of promising therapies because of the commonly held belief that 'absence of evidence is evidence of absence' [39]. This is compounded by the fact that delta inflation can conceal the low statistical power of a trial, thus falsely assuring clinicians that a true difference has been ruled out by a trial with a low type II error rate. Thirdly, the conduct of trials with delta inflation may represent a waste of resources because it undermines their scientific and clinical validity and value to society.

If delta inflation exists, several approaches might minimize its impact. Firstly, not only should predicted delta be reported [40], but also should it be justified by a referenced review of available evidence or a statement about biological plausibility or the MCID, especially when predicted delta exceeds a nominal value such as $3 \%[18,24]$. Results of trials should report confidence intervals for delta rather than $P$ values and should emphasize that the results excluded a difference greater than the upper confidence interval rather than stating that the results failed to find a statistically significant difference $[11,13,37]$. A 'buffer' to account for delta inflation could be built into power calculations as is now done for anticipated rates of drop out and loss to follow up. Moreover, the use of mortality as the only accepted primary outcome for trials of therapies for critical illness should be reconsidered, because few therapies in critical care are ultimately shown to reduce mortality $[1,23]$. Consideration might be given to the use of composite [41] or weighted composite $[42,43]$ endpoints in which each part of the composite is weighted according to its relative value. For example, a composite endpoint might be comprised of mortality, renal replacement therapy, mechanical ventilation, nonambulatory status, or receiving nutritional support at some pre-determined time point (e.g., 28 or 60 days). More research related to long-term outcomes in critical illness and their relative values will be needed to inform the choice of components of composite endpoints [44].

There are several limitations of our study. As we limited our search to five high-impact journals, it is possible that we have overestimated the prevalence of delta inflation because of omission of trials that more accurately predicted delta in other journals. This is unlikely because high-impact journals are more likely to publish 'positive' trials and those with larger sample sizes and larger effects, and thus our analysis may have underestimated the prevalence and impact of delta inflation. For the sake of homogeneity, we limited our analysis to critical care trials that utilized mortality as a primary endpoint, and 
therefore our findings may not be generalizable to trials in other specialties and those using other primary outcomes. Nonetheless, the same pressures faced by critical care investigators may be experienced by investigators in other fields pursuing other outcomes who may likewise be susceptible to delta inflation. Determination of the prevalence of delta inflation in other arenas will require specific study.

\section{Conclusions}

Delta inflation, a systematic overestimation in predictions of treatment effect size during trial design, is common in randomized controlled trials of mortality in critical care medicine. Reliable methods for predicting delta during study design and better reporting of the basis for these predictions are needed to minimize the risk of trial failure from type II statistical errors and resulting waste of research resources. Consideration should be given to designing such trials with other clinically meaningful primary endpoints. Critical care practitioners and investigators must be aware that because of delta inflation, negative results in randomized controlled trials do not rule out efficacy of the therapies evaluated.

\section{Key messages}

- Most therapies for adult critical illness fail to demonstrate efficacy in randomized controlled trials.

- In the design of randomized controlled trials, investigators must determine a realistic estimate of the effect size (delta) of the therapy on an outcome of interest such as mortality.

- In randomized controlled trials in critical care, predicted delta almost always exceeds the delta observed in the trial data.

- This 'delta inflation' is a potential reason that most such trials fail to demonstrate efficacy.

- Critical care practitioners and investigators must bear in mind that 'absence of evidence is not evidence of absence'.

\section{Additional material}

Additional file 1: Table S2. Selected characteristics of studies included in

the analysis.

\section{Abbreviations}

delta: effect size; MCID: minimal clinically important difference.

\section{Competing interests}

The authors declare that they have no competing interests.

\section{Authors' contributions}

SKA conceived the idea for the article, performed the data abstraction and analysis and wrote the manuscript. JMOB assisted with conception of the article and with writing and editing of the manuscript. DRR assisted with data collection and analysis, and analysis plan.

\section{Author Details}

1Department of Critical Care, Jordan Valley Medical Center, 3580 West 9000 South, West Jordan, Utah, 84088, USA, 2Department of Family Medicine, University of Virginia Health System, 1215 Lee Street, Charlottesville, Virginia, 22908, USA and ${ }^{3}$ Department of Internal Medicine, The Ohio State University College of Medicine, 410 West 10th Avenue, Columbus, Ohio, 43210, USA

Received: 23 November 2009 Revised: 7 February 2010

Accepted: 29 April 2010 Published: 29 April 2010

\section{References}

1. Ospina-Tascon GA, Buchele GL, Vincent JL: Multicenter, randomized, controlled trials evaluating mortality in intensive care: doomed to fail? Crit Care Med 2008, 36:1311-1322.

2. Berghe $G$ van den, Wouters $P$, Weekers F, Verwaest $C$, Bruyninckx F, Schetz $M$, Vlasselaers D, Ferdinande $P$, Lauwers $P$, Bouillon R: Intensive insulin therapy in critically ill patients. N Engl J Med 2001, 345:1359-1367.

3. Berghe $G$ Van den, Wilmer A, Hermans G, Meersseman W, Wouters PJ, Milants I, Van Wijngaerden E, Bobbaers H, Bouillon R: Intensive insulin therapy in the medical ICU. NEngl J Med 2006, 354:449-461.

4. The NICE-SUGAR Study Investigators: Intensive versus conventional glucose control in critically ill patients. N Engl J Med 2009, 360:1283-1297.

5. Annane D, Sébille V, Charpentier C, Bollaert PE, François B, Korach JM, Capellier G, Cohen Y, Azoulay E, Troché G, Chaumet-Riffaud P, Bellissant E: Effect of treatment with low doses of hydrocortisone and fludrocortisone on mortality in patients with septic shock. JAMA 2002 , 288:862-871.

6. Sprung CL, Annane D, Keh D, Moreno R, Singer M, Freivogel K, Weiss YG, Benbenishty J, Kalenka A, Forst H, Laterre PF, Reinhart K, Cuthbertson BH, Payen D, Briegel J, CORTICUS Study Group: Hydrocortisone therapy for patients with septic shock. N Engl J Med 2008, 358:111-124.

7. Brunkhorst FM, Engel C, Bloos F, Meier-Hellmann A, Ragaller M, Weiler N, Moerer O, Gruendling M, Oppert M, Grond S, Olthoff D, Jaschinski U, John S, Rossaint R, Welte T, Schaefer M, Kern P, Kuhnt E, Kiehntopf M, Hartog C, Natanson C, Loeffler M, Reinhart K, German Competence Network Sepsis (SepNet): Intensive insulin therapy and pentastarch resuscitation in severe sepsis. NEngl J Med 2008, 358(2):125-139.

8. Charles P, Giraudeau B, Dechartres A, Baron G, Ravaud P: Reporting of sample size calculation in randomised controlled trials: review. $B M$ 2009, 338:b1732.

9. Moher D, Schulz KF, Altman D, for the CONSORT Group: The CONSORT statement: revised recommendations for improving the quality of reports of parallel-group randomized trials. JAMA 2001, 285:1987-1991.

10. Chan KB, Man-Son-Hing M, Molnar FJ, Laupacis A: How well is the clinical importance of study results reported? An assessment of randomized controlled trials. CMAJ 2001, 165:1197-1202.

11. Schulz KF, Grimes DA: Sample size calculations in randomised trials: mandatory and mystical. Lancet 2005, 365:1348-1353.

12. Matthews JN: Small clinical trials: are they all bad? Stat Med 1995, 14:115-126.

13. Goodman SN, Berlin JA: The use of predicted confidence intervals when planning experiments and the misuse of power when interpreting results. Ann Intern Med 1994, 121:200-206.

14. Guyatt $\mathrm{GH}$, Mills EJ, Elbourne D: In the era of systematic reviews, does the size of an individual trial still matter. PLOSMed 2008, 5:e4.

15. Harvey S, Harrison DA, Singer M, Ashcroft J, Jones CM, Elbourne D, Brampton W, Williams D, Young D, Rowan K, PAC-Man study collaboration: Assessment of the clinical effectiveness of pulmonary artery catheters in management of patients in intensive care (PAC-Man): a randomised controlled trial. Lancet 2005, 366:472-477. 
16. The National Heart LaBIARDSACTN: Efficacy and safety of corticosteroids for persistent acute respiratory distress syndrome. NEngl J Med 2006, 354:1671-1684

17. Abraham E, Reinhart K, Opal S, Demeyer I, Doig C, Rodriguez AL, Beale R, Svoboda P, Laterre PF, Simon S, Light B, Spapen H, Stone J, Seibert A, Peckelsen C, De Deyne C, Postier R, Pettilä V, Artigas A, Percell SR, Shu V, Zwingelstein C, Tobias J, Poole L, Stolzenbach JC, Creasey AA, OPTIMIST Trial Study Group: Efficacy and safety of tifacogin (recombinant tissue factor pathway inhibitor) in severe sepsis: a randomized controlled trial. JAMA 2003, 290:238-247.

18. Finfer S, Bellomo R, Boyce N, French J, Myburgh J, Norton R, SAFE Study Investigators: A comparison of albumin and saline for fluid resuscitation in the intensive care unit. N Engl J Med 2004, 350:2247-2256.

19. Bernard GR, Vincent JL, Laterre PF, LaRosa SP, Dhainaut JF, LopezRodriguez A, Steingrub JS, Garber GE, Helterbrand JD, Ely EW, Fisher CJ Jr, Recombinant human protein C Worldwide Evaluation in Severe Sepsis (PROWESS) study group: Efficacy and safety of recombinant human activated protein C for severe sepsis. N Engl J Med 2001, 344:699-709.

20. Rivers E, Nguyen B, Havstad S, Ressler J, Muzzin A, Knoblich B, Peterson E, Tomlanovich M, Early Goal-Directed Therapy Collaborative Group: Early goal-directed therapy in the treatment of severe sepsis and septic shock. NEngl J Med 2001, 345:1368-1377.

21. Esteban A, Anzueto A, Frutos F, Alía I, Brochard L, Stewart TE, Benito S, Epstein SK, Apezteguía C, Nightingale P, Arroliga AC, Tobin MJ, Mechanical Ventilation International Study Group: Characteristics and outcomes in adult patients receiving mechanical ventilation: a 28-day international study. JAMA 2002, 287:345-355.

22. Sloan EP, Koenigsberg M, Gens D, Cipolle M, Runge J, Mallory MN, Rodman G Jr: Diaspirin cross-linked hemoglobin (DCLHb) in the treatment of severe traumatic hemorrhagic shock: a randomized controlled efficacy trial. JAMA 1999, 282:1857-1864.

23. Weaver CS, Leonardi-Bee J, Bath-Hextall FJ, Bath PM: Sample size calculations in acute stroke trials: a systematic review of their reporting, characteristics, and relationship with outcome. Stroke 2004 35:1216-1224.

24. Raju TN, Langenberg P, Sen A, Aldana O: How much 'better' is good enough? The magnitude of treatment effect in clinical trials. Am J Dis Child 1992, 146:407-411.

25. Moher D, Dulberg CS, Wells GA: Statistical power, sample size, and thei reporting in randomized controlled trials. JAMA 1994, 272:122-124.

26. Chan AW, Hrobjartsson A, Jorgensen KJ, Gotzsche PC, Altman DG: Discrepancies in sample size calculations and data analyses reported in randomised trials: comparison of publications with protocols. $B M J$ 2008, 337:a2299.

27. Chalmers I, Matthews R: What are the implications of optimism bias in clinical research? Lancet 2006, 367:449-450.

28. Aberegg SK, O'Brien J Jr, Khoury P, Patel R, Arkes HR: The influence of treatment effect size on willingness to adopt a therapy. Med Decis Making 2009, 29:599-605.

29. Gould ALL: Planning and revising the sample size for a trial. Stat Med 1995, 14:1039-1051.

30. Naylor CD, Llewellyn-Thomas HA: Can there be a more patient-centred approach to determining clinically important effect sizes for randomized treatment trials? J Clin Epidemiol 1994, 47:787-795.

31. Chan KB, Man-Son-Hing M, Molnar FJ, Laupacis A: How well is the clinical importance of study results reported? An assessment of randomized controlled trials. CMAJ 2001, 165:1197-1202.

32. Decullier $E$, Chan AW, Chapuis F: Inadequate dissemination of phase I trials: a retrospective cohort study. PLoS Med 2009, 6:e1000034.

33. Bedard PL, Krzyzanowska MK, Pintilie M, Tannock IF: Statistical power of negative randomized controlled trials presented at American Society for Clinical Oncology annual meetings. J Clin Oncol 2007, 25:3482-3487.

34. Hebert RS, Wright SM, Dittus RS, Elasy TA: Prominent medical journals often provide insufficient information to assess the validity of studies with negative results. J Negat Results Biomed 2002, 1:1

35. National Heart, Lung, and Blood Institute Acute Respiratory Distress Syndrome (ARDS) Clinical Trials Network, Wiedemann HP, Wheeler AP, Bernard GR, Thompson BT, Hayden D, deBoisblanc B, Connors AF Jr, Hite $\mathrm{RD}$, Harabin $\mathrm{AL}$ : Comparison of two fluid-management strategies in acute lung injury. N Eng/ J Med 2006, 354:2564-2575.

36. Rivers EP: Fluid-management strategies in acute lung injury -- liberal, conservative, or both? N Engl J Med 2006, 354:2598-2600.
37. Feinstein $A R$, Concato J: The quest for "power": contradictory hypotheses and inflated sample sizes. J Clin Epidemiol 1998, 51:537-545.

38. Halpern SD, Karlawish JH, Berlin JA: The continuing unethical conduct of underpowered clinical trials. JAMA 2002, 288:358-362

39. Altman DG, Bland JM: Absence of evidence is not evidence of absence. Aust Vet J 1996, 74:311.

40. Ioannidis JP, Evans SJ, Gøtzsche PC, O'Neill RT, Altman DG, Schulz K, Moher D, CONSORT Group: Better reporting of harms in randomized trials: an extension of the CONSORT statement. Ann Intern Med 2004, 141:781-788

41. Freemantle N, Calvert M, Wood J, Eastaugh J, Griffin C: Composite outcomes in randomized trials: greater precision but with greater uncertainty? JAMA 2003, 289:2554-2559.

42. Lim E, Brown A, Helmy A, Mussa S, Altman DG: Composite outcomes in cardiovascular research: a survey of randomized trials. Ann Intern Med 2008, 149:612-617.

43. Ferreira-González I, Busse JW, Heels-Ansdell D, Montori VM, AkI EA, Bryant DM, Alonso-Coello P, Alonso J, Worster A, Upadhye S, Jaeschke R, Schünemann HJ, Permanyer-Miralda G, Pacheco-Huergo V, DomingoSalvany A, Wu P, Mills EJ, Guyatt GH: Problems with use of composite end points in cardiovascular trials: systematic review of randomised controlled trials. BMJ 2007, 334:786.

44. Dowdy DW, Eid MP, Sedrakyan A, Mendez-Tellez PA, Pronovost PJ, Herridge MS, Needham DM: Quality of life in adult survivors of critical illness: a systematic review of the literature. Intensive Care Med 2005, 31:611-620

\section{doi: $10.1186 /$ cc8990}

Cite this article as: Aberegg et al., Delta inflation: a bias in the design of randomized controlled trials in critical care medicine Critical Care 2010, 14:R77

\section{Submit your next manuscript to BioMed Central and take full advantage of:}

- Convenient online submission

- Thorough peer review

- No space constraints or color figure charges

- Immediate publication on acceptance

- Inclusion in PubMed, CAS, Scopus and Google Scholar

- Research which is freely available for redistribution 